\title{
Upregulation of miRNA-140-5p inhibits inflammatory cytokines in acute lung injury through the MyD88/NF-кB signaling pathway by targeting TLR4
}

\author{
YE YANG ${ }^{1}$, DONGDONG LIU ${ }^{2}$, YIN XI $^{2}$, JUAN LI ${ }^{1}$, BIN LIU $^{1}$ and JUNJIE $\mathrm{LI}^{3}$ \\ ${ }^{1}$ Department of Medical Oncology, Sichuan Cancer Hospital, Chengdu, Sichuan 610041; \\ ${ }^{2}$ Department of Respiratory Medicine, The First Affiliated Hospital of Guangzhou Medical University, Guangzhou, \\ Guangdong 510120; ${ }^{3}$ Surgical Center, Sichuan Cancer Hospital, Chengdu, Sichuan 610041, P.R. China
}

Received February 1, 2018; Accepted August 21, 2018

DOI: $10.3892 /$ etm.2018.6692

\begin{abstract}
The present study was designed to determine the effect of miR-140-5p on acute lung injury (ALI) and the associated inflammation induced. As a result, miR-140-5p expression in mice with ALI was suppressed when compared with the normal group. Downregulation of miR-140-5p increased the levels of inflammatory factors induced by ALI [including tumor necrosis factor- $\alpha$, interleukin (IL)-1 $\beta$, IL-6 and myeloperoxidase] in an in vitro model of human lung A549 cells. Downregulation of miR-140-5p also induced the protein expression of Toll-like receptor 4 (TLR4), myeloid differentiation primary response 88 (MyD88) and nuclear factor (NF)- $\mathrm{kB}$ in an in vitro model. Overexpression of miR-140-5p reduced the levels of inflammation in the in vitro model of ALI via the suppression of the TLR4/MyD88/NF- $\mathrm{kB}$ signaling pathway. The inhibition of TLR4 using a TLR4 inhibitor reduced the proinflammation effects of anti-miR-140-5p in the in vitro model of ALI. The $\mathrm{NF}-\kappa \mathrm{B}$ inhibitor also inhibited the proinflammation effects of anti-miR-140-5p in the in vitro model of ALI. Overall, the results of the present study indicated that miR-140-5p inhibited ALI-induced inflammation via the TLR4/MyD88/NF- $\mathrm{KB}$ signaling pathway.
\end{abstract}

\section{Introduction}

Acute Lung Injury (ALI) and acute respiratory distress syndrome (ARDS) are two types of common and complex inflammatory lung diseases (1). As a kind of

Correspondence to: Dr Junjie Li, Surgical Center, Sichuan Cancer Hospital, 55, Section 4, South Ren min Road, Chengdu, Sichuan 610041, P.R. China

E-mail: iwiory2006562@126.com

Key words: microRNA-140-5p, acute lung injury, inflammation, Toll-like receptor 4 , myeloid differentiation primary response 88 , nuclear factor- $\mathrm{\kappa} \mathrm{B}$ novel gene regulatory molecule, microRNAs play an important role in various complicated diseases, including ALI (2).

ARDS is a common and major inflammatory lung disease, characterized by rapid progression. It is estimated that there are 190,000 newly diagnosed cases of ALI in the United States alone each year, 75,000 of whom die annually (3). In China, the incidence of ALI/ARDS is higher, with mortality rate as high as $52 \%$ (2). In recent years, it has been noted that miRNAs play an important role in multiple biological processes and signal transduction pathways of ALI/ARDS (4).

The expression changes of miRNAs are associated with immune response, inflammatory signaling pathways and pathogenesis of inflammatory lung diseases, including ALI, hence, miRNAs can be considered as new therapeutic target (4). Although miRNAs change the expression of related genes moderately, it may greatly affect the expression of a large number of downstream genes, thereby influencing a variety of biological processes. Therefore, miRNAs might be potentially used as one of the markers $(5,6)$.

Toll-like receptor (TLR) family serves both as signal molecules and receptors of lipopolysaccharide (LPS) (7). TLR4, a member of TLR family, is mainly distributed on the surface of mononuclear macrophage, which mediates the intracellular conduction of LPS inflammation signals, and is the preferential receptor of LPS (8). Nuclear factor (NF)- $\mathrm{BB}$ collectively refers to many DNA binding proteins which specifically bind to $\mathrm{\kappa B}$ site of promoters of a variety of genes, and promotes transcription, which plays an important role in immune response, inflammatory response and cell growth regulation (7). NF- $\kappa B$ signal pathway is the most important downstream pathway among all signal transduction pathways mediated by LPS, suggesting that TLR4/NF- $\mathrm{BB}$ pathway may be the key target to trigger inflammatory response and organ injury (9). Zhang and $\mathrm{Xu}(10)$ has indicated that miRNA-140-5p regulates hypoxia-mediated human pulmonary artery smooth muscle cell proliferation. Herein, the aim of the present study was to investigate the function of miRNA-140-5p in ts ALI and its regulatory mechanism. 


\section{Materials and methods}

Animals and ethics statement. C57/BL6 mice, 6-8 weeks of age, were purchased from Guangdong Medical Laboratory Animal Centre (Guangzhou, China). The mice were randomly divided into two groups, control group $(\mathrm{n}=6)$ and Model group $(\mathrm{n}=8)$. In Model group, mice were inhaled with $1,000 \mu \mathrm{g} / \mathrm{ml}$ LPS for $1 \mathrm{~h}$ at $3 \mathrm{~h}$ intervals over a period of $8 \mathrm{~h}$. In control group, mice were inhaled with normal saline for $1 \mathrm{~h}$ at $3 \mathrm{~h}$ intervals over a period of $8 \mathrm{~h}$. The experimental procedures conformed to the Guide for the Care and Use of Laboratory Animal, and all of the procedures were approved by the Institutional Ethics Committee of Sichuan Cancer Hospital (Sichuan, China).

Enzyme-linked immunosorbent assay (ELISA) kits. Lung tissue or transfection cells were extracted in lysis buffer (Beyotime Institute of Biotechnology, Nanjing, China) and Protein concentration was measured by the Pierce ${ }^{\mathrm{TM}} \mathrm{BCA}$ protein assay kit Beyotime Institute of Biotechnology, Nanjing, China). $10 \mu \mathrm{g}$ extracts was used to analyze tumor necrosis factor (TNF)- $\alpha$, interleukin (IL)-1 $\beta$, IL-6 and MPO levels using ELISA kits.

Histopathology. Lung tissue samples were fixed in $4 \%$ paraformaldehyde for $24 \mathrm{~h}$, embedded in paraffin, and cut into $5-\mu \mathrm{m}$ thick sections. Lung tissue samples was stained with hematoxylin and eosin assay for $5 \mathrm{~min}$ and observed using a phase fluorescence microscope (Axio Observer; Carl Zeiss AG, Oberkochen, Germany).

Reverse transcription-quantitative polymerase chain reaction $(R T-q P C R)$. Total RNA from serum was extracted using TRIzol (Thermo Fisher Scientific, Inc., Waltham, MA, USA) according to the manufacturer's protocol. cDNA was reverse transcribed, which was performed as described using the PrimeScript $^{\mathrm{TM}}$ RT reagent kit (Takara Bio, Inc., Otsu, Japan). Relative gene expression was quantified using ABI 7900HT Real-Time PCR System (Applied Biosystems; Thermo Fisher Scientific, Inc.) with SYBR ${ }^{\circledR}$ Premix Ex Taq ${ }^{\mathrm{TM}}$ II kit (Takara Bio, Inc.). The thermocycling conditions were as follows: $94^{\circ} \mathrm{C}$ for $10 \mathrm{~min}$, followed by 40 cycles of $94^{\circ} \mathrm{C}$ for $15 \mathrm{sec}, 55^{\circ} \mathrm{C}$ for $30 \mathrm{sec}$ and $72^{\circ} \mathrm{C}$ for $30 \mathrm{sec}$. The relative expression levels were analyzed using the $2^{-\Delta \Delta \mathrm{Cq}}$ method (11).

Cell culture and treatment. Human lung A549 cells were maintained in Dulbecco's modified Eagle's medium (DMEM; Gibco; Thermo Fisher Scientific, Inc.) containing 10\% fetal calf serum (FCS; Gibco; Thermo Fisher Scientific, Inc.), $100 \mathrm{U} / \mathrm{ml}$ penicillin and $100 \mu \mathrm{g} / \mathrm{ml}$ streptomycin (Gibco; Thermo Fisher Scientific, Inc.) at $5 \% \mathrm{CO}_{2}$ at $37^{\circ} \mathrm{C}$.

Transfection. miRNA-140-5p mimic and mimic control (mimic-NC) were purchased from Sangon Biotech Co., Ltd. (Shanghai, China). A549 cell was co-transfected with $20 \mathrm{nM}$ miRNA-140-5p mimic and mimic control (mimic-NC) using Lipofectamine 3000 (Invitrogen, Guangzhou, China). After transfection for $4 \mathrm{~h}$, old medium was removed and new medium was added into cell. After transfection for $48 \mathrm{~h}, \mathrm{~A} 549$ cell was treated by $100 \mathrm{ng} / \mathrm{ml}$ of LPS for $4 \mathrm{~h}$, and then analyzed other study.
Dual luciferase assays. 293 cells were cotransfected with TLR4 luciferase reporter construct with miR-140-5p using Lipofectamine 2000 transfection reagent (Thermo Fisher Scientific, Inc.) for $48 \mathrm{~h}$. Luciferase activity was assayed using a Dual-Luciferase Reporter Assay System (Promega Corporation, Madison, WI, USA).

Western blotting. Transfection cells were extracted in lysis buffer (Beyotime Institute of Biotechnology, Nanjing, China) and Protein concentration was measured by the Pierce ${ }^{\mathrm{TM}} \mathrm{BCA}$ protein assay kit (Beyotime Institute of Biotechnology, Nanjing, China). Equal amount of the extracts $(50 \mu \mathrm{g})$ were loaded and separated in a $8-10 \%$ polyacrylamide gel, then proteins were transferred onto a PVDF membrane (EMD Millipore, Billerica, MA, USA). Membranes were incubated with TLR4, myeloid differentiation primary response 88 (MyD88), NF- $\mathrm{kB}$, and GADPH (Santa Cruz Biotechnology, Inc., Dallas, TX, USA) at $4^{\circ} \mathrm{C}$ over-night. Membranes were incubated with goat anti-rabbit HRP (Santa Cruz Biotechnology, Inc.; 1:2,000 dilution).

Immunofluorescence. Cell was washed with PBS and fixed with $4 \%$ paraformaldehyde for $15 \mathrm{~min}$, and blocked with $0.5 \mathrm{ml}$ PBS containing $0.1 \%$ Triton X-100 and $1 \%$ BSA at room temperature for $1 \mathrm{~h}$. Cell were incubated with TLR4 (Santa Cruz Biotechnology, Inc.) at $4^{\circ} \mathrm{C}$ over-night. Cell were then washed with PBS and incubated with Alexa 555 labelled Rabbit Anti-Goat secondary antibody (Santa Cruz Biotechnology, Inc.) in the dark for $1 \mathrm{~h}$ at room temperature and stained with DAPI for $15 \mathrm{~min}$ in the dark. Images cells were obtained by using a phase fluorescence microscope (Axio Observer; Carl Zeiss AG).

Statistical analysis. All data are expressed as the mean \pm standard deviation. Data were analyzed using SPSS 17.0 software (SPSS, Inc., Chicago, IL, USA). Independent-samples t-tests between two groups and one-way analysis of variance for multiple comparisons with Dunnett's post hoc test were performed. $\mathrm{P}<0.05$ was considered to indicate a statistically significant difference.

\section{Results}

miR-140-5p expression in mice with ALI. The expression of miR-140-5p was examined in ALI and control mice. Firstly, HE staining showed there was diffuse alveolar damage in ALI group, compared with control group (Fig. 1A). Then, the levels of TNF- $\alpha$, IL-1 $\beta$, IL- 6 and MPO were increased in ALI group in comparison to control group (Fig. 1B-E). As shown in Fig. 1G, miR-140-5p expression in mice with ALI was suppressed, compared with normal control group. Therefore, miR-140-5p may be a key factor for ALI.

miR-140-5p regulated inflammation in in vitro model of $A L I$. To explore whether miR-140-5p regulated inflammation of ALI, the levels of TNF- $\alpha$, IL-1 $\beta$, IL- 6 and MPO were measured in this study. As shown in Fig. 2A and B, anti-miR-140-5p mimics or miR-140-5p mimics inhibited or increased the expression of miR-140-5p in in vitro model of ALI, compared with that in the control group. The levels of 


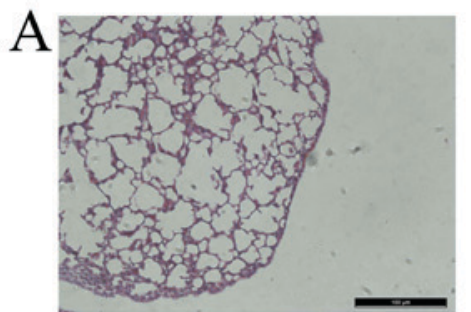

Control
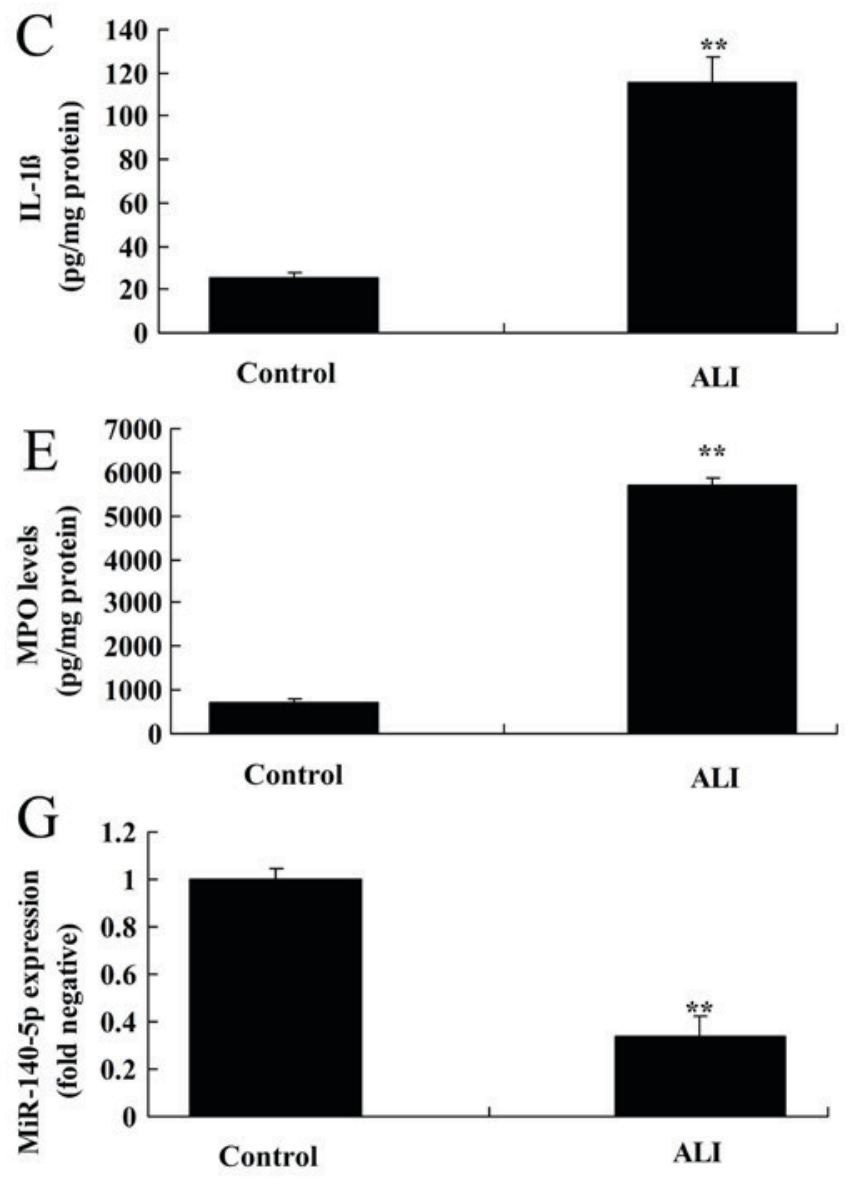
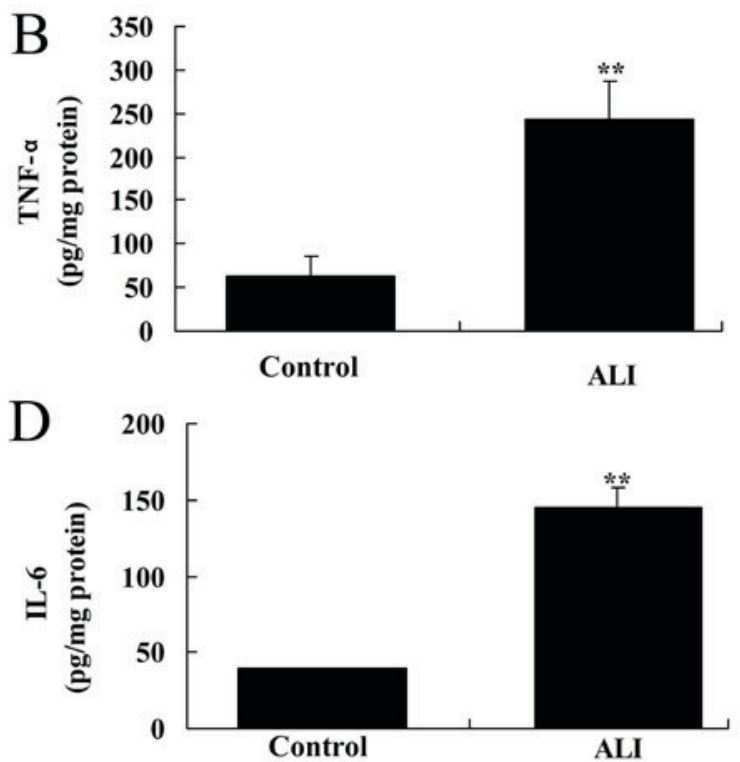

F

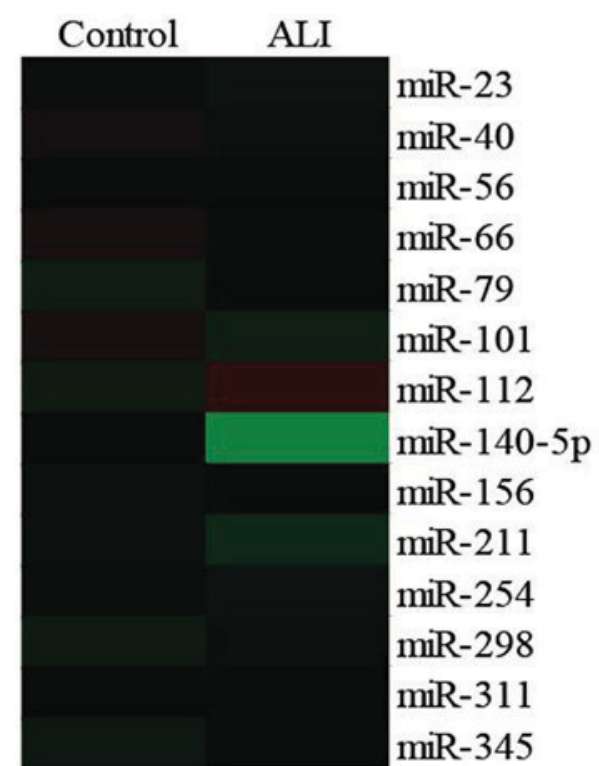

Figure 1. miR-140-5p expression in mice with ALI. (A) Hematoxylin and eosin staining (scale bars, $100 \mu \mathrm{m})$. (B) TNF- $\alpha$, (C) IL-1 $\beta$, (D) IL-6 and (E) MPO protein levels. (F) The miR-140-5p expression gene chip and $(\mathrm{G})$ the results of reverse transcription-quantitative polymerase chain reaction. ${ }^{* *} \mathrm{P}<0.01$ vs. control group. ALI, acute lung injury; miR, microRNA; TNF- $\alpha$, tumor necrosis factor- $\alpha$; IL, interleukin; MPO, myeloperoxidase.

TNF- $\alpha$, IL-1 $\beta$, IL-6 and MPO were significantly elevated in in vitro model of ALI following miR-140-5p down-regulation, compared with control group (Fig. 2C-F). Over-expression of miR-140-5p inhibited the levels of TNF- $\alpha$, IL-1 $\beta$, IL-6 and $\mathrm{MPO}$ in in vitro model of ALI, in comparison with control group (Fig. 2G-J). Hence, miR-140-5p may regulate the inflammation of ALI.

miR-140-5p regulated inflammation in in vitro model of ALI by MyD88/NF-KB signaling pathway by targeting TLR4. Next TLR4/MyD88/NF- $\kappa \mathrm{B}$ signaling pathway was measured in this study to determine the mechanism function of miR-140-5p in ALI. As shown in Fig. 3A and B, putative binding sequences of miR-140-5p in the 3'UTR of TLR4, and the luciferase assay of miR-140-5p was reduced in WT group, compared with that in the control group. Immunofluorescence showed that over-expression of miR-140-5p suppressed TLR4 protein expression in in vitro model of ALI, compared with control group (Fig. 3C). Down-regulation of miR-140-5p induced TLR4/MyD88/NF- $\kappa$ B signaling pathway in in vitro model of $\mathrm{ALI}$, in comparison to control group (Fig. 4A-D). Over-expression of miR-140-5p suppressed TLR4/MyD88/NF- $\kappa \mathrm{B}$ signaling pathway in in vitro model of ALI, compared with control group (Fig. 4E-H). Hence, miR-140-5p may reduce the inflammation of ALI by regulating TLR4/MyD88/NF- $\mathrm{B}$ signaling pathway in vitro.

The inhibition of TLR4 suppressed the effects of TLR4/MyD88/NF- $\kappa B$ signaling pathway on anti-miR-140-5p in $A L I$ in vitro. To confirm the mechanism function of TLR4 in miR-140-5p in ALI in vitro, TLR4 inhibitor (TAK-242, $0.5 \mathrm{nM}, 48 \mathrm{~h}$ ) was used to inhibit the expression of TLR4. As shown in Fig. 5A-D, TLR4 inhibitor suppressed 

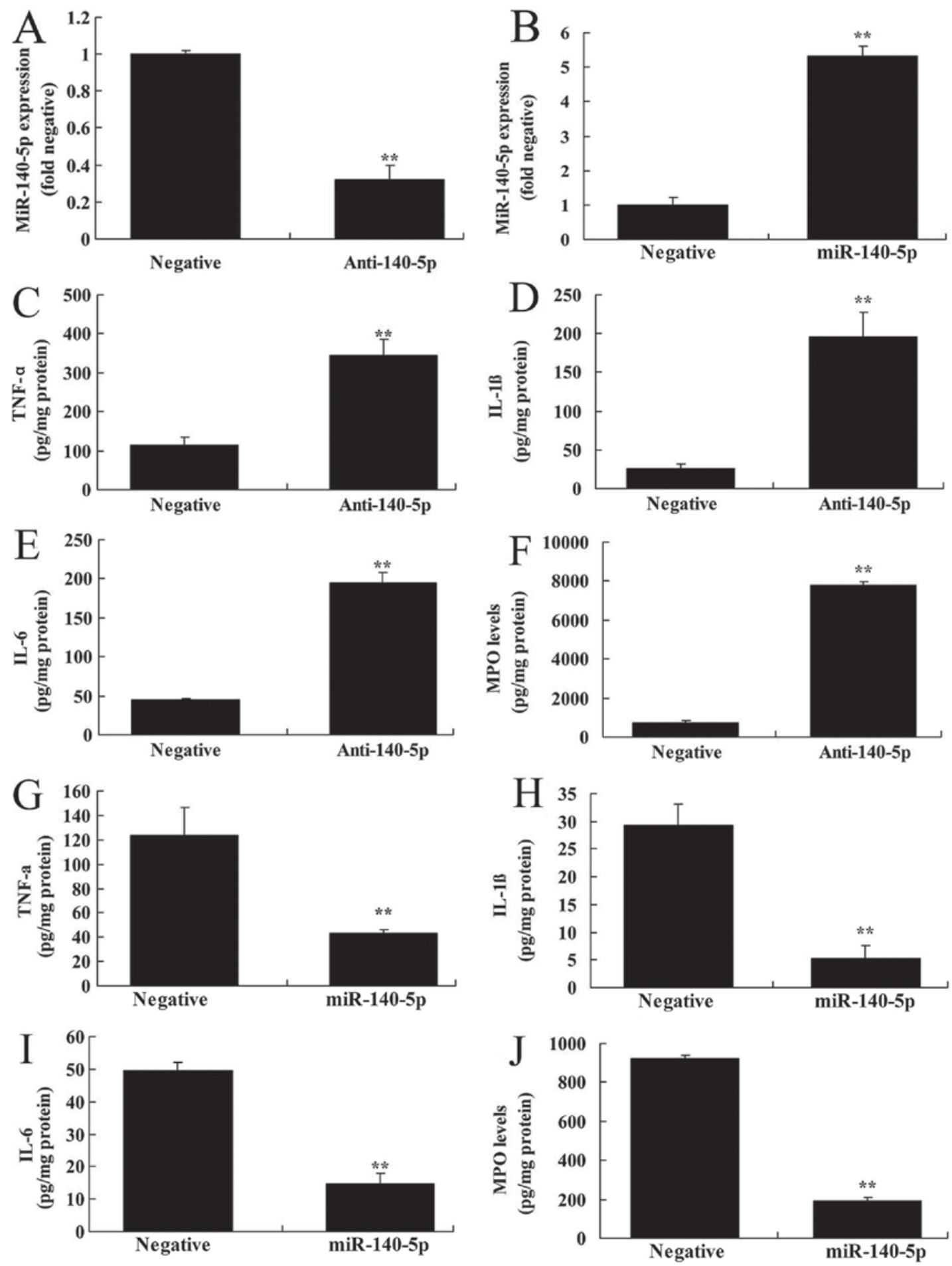

Figure 2. miR-140-5p regulates inflammation in an in vitro model of acute lung injury. Reverse transcription-quantitative polymerase chain reaction was performed to determine the expression of (A and B) miR-140-5p in the anti-140-5p and miR-140-5p groups, as well as that of (C) TNF- $\alpha$, (D) IL-1 $\beta$, (E) IL-6 and (F) MPO levels following of miR-140-5p downregulation; and also (G) TNF- $\alpha$, (H) IL-1 $\beta$, (I) IL-6 and (J) MPO levels following miR-140-5p overexpression. ${ }^{* *} \mathrm{P}<0.01$ vs. negative control group. miR, microRNA; Anti-140-5p, downregulation of miR-140-5p group; miR-140-5p, overexpression of miR-140-5p group; TNF- $\alpha$, tumor necrosis factor- $\alpha$; IL, interleukin; MPO, myeloperoxidase.

TLR4/MyD88/NF- $\mathrm{BB}$ signaling pathway in in vitro model of ALI following miR-140-5p down-regulation, compared with miR-140-5p down-regulation group. In addition, TLR4 inhibitor also reduced the levels of TNF- $\alpha$, IL-1 , IL- 6 and MPO in in vitro model of ALI following miR-140-5p down-regulation, compared with miR-140-5p down-regulation group (Fig. 5E-H).
The inhibition of $N F-\kappa B$ suppressed the effects of $N F-\kappa B$ signaling pathway on anti-miR-140-5p in ALI in vitro. Meanwhile, NF- $\mathrm{BB}$ inhibitor (JSH-23, $2 \mu \mathrm{M}, 48 \mathrm{~h}$ ) was utilized to suppress the protein expression of NF- $\mathrm{KB}$ in ALI in vitro following miR-140-5p down-regulation, compared with miR-140-5p down-regulation group (Fig. 6A and B). NF-kB inhibitor also inhibited the levels of TNF- $\alpha$, IL-1 $\beta$, IL- 6 and MPO in ALI in vitro following 
A

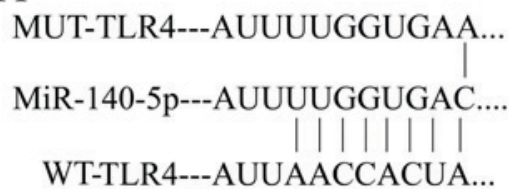

WT-TLR4---AUUAACCACUA...

$\mathrm{C}$

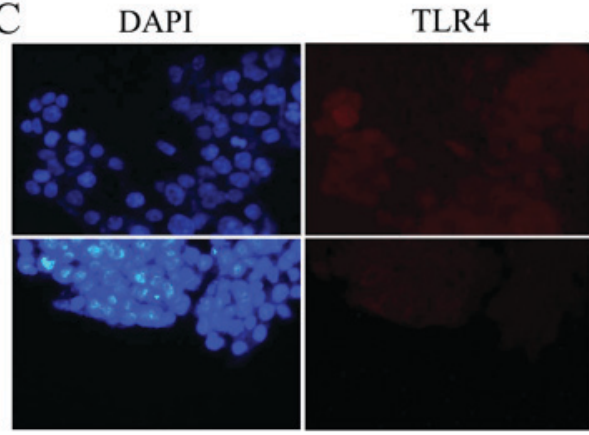

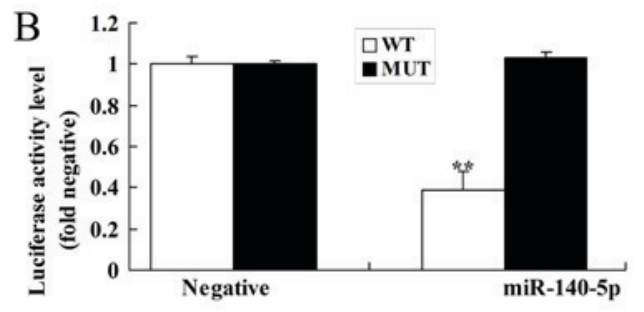

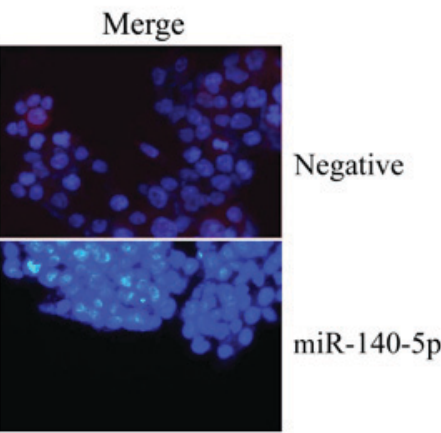

Figure 3. miR-140-5p regulates TLR4 in the in vitro acute lung injury model. (A) Putative binding sequences of miR-140-5p in the 3'-untranslated region of TLR4 and (B) the luciferase assay. (C) Immunofluorescence for TLR4 protein expression (magnification, $\mathrm{x} 100$ ). ${ }^{* *} \mathrm{P}<0.01$ vs. negative control group. miR, microRNA; miR-140-5p, overexpression of miR-140-5p group; MUT, mutant; WT, wild type; TLR4, Toll-like receptor 4.

A
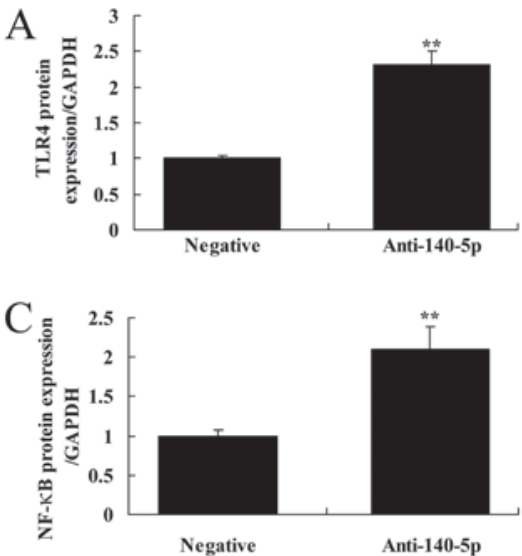

$\mathrm{E}$
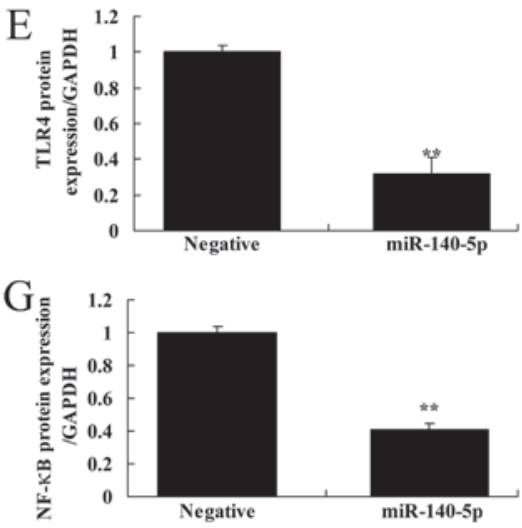

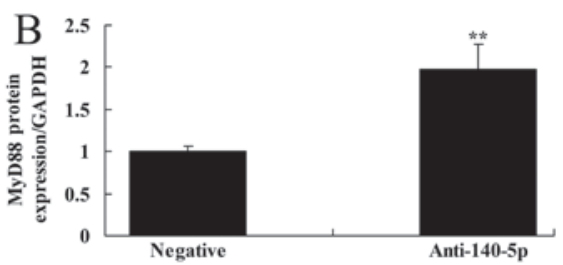

$\mathrm{D}$
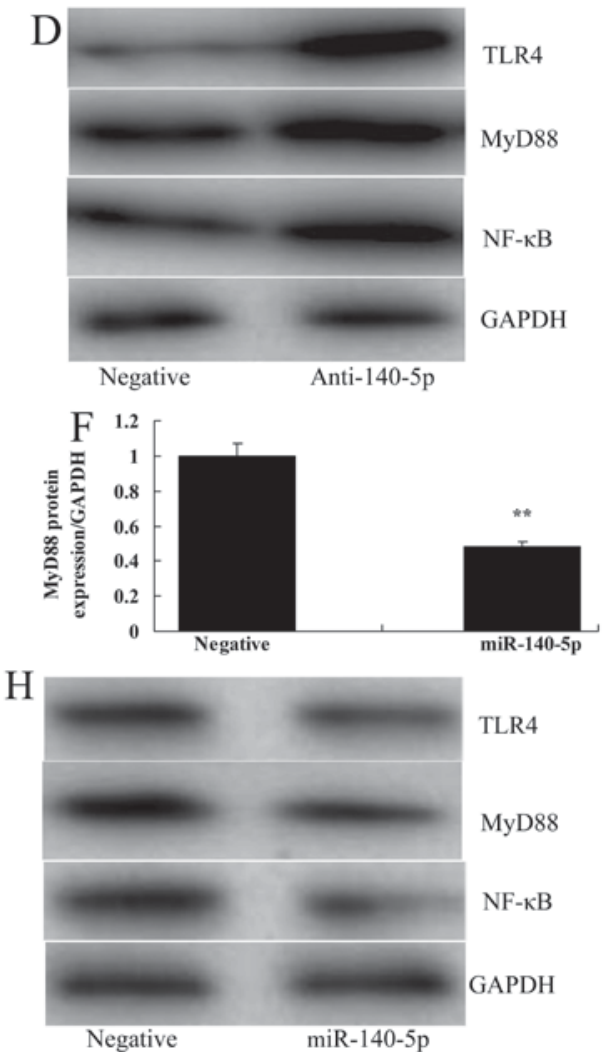

Figure 4. miR-140-5p regulates inflammation in the in vitro acute lung injury model through the MyD88/NF-KB signaling pathway by targeting TLR4. (A) TLR4, (B) MyD88 and (C) NF- $\kappa$ B protein expression was statistically analyzed. (D) Western blotting assays for the (E) TLR4, (F) MyD88 and (G) NF- $\kappa$ B signaling pathway were performed following miR-140-5p downregulation, as well as following $(\mathrm{H})$ the overexpression of miR-140-5p. ${ }^{* *} \mathrm{P}<0.01 \mathrm{vs}$. negative control group. miR, microRNA; Anti-140-5p, downregulation of miR-140-5p group; miR-140-5p, over-expression of miR-140-5p; TLR4, Toll-like receptor 4; MyD88, myeloid differentiation primary response $88 ; \mathrm{NF}-\kappa \mathrm{B}$, nuclear factor- $\kappa \mathrm{B}$. 

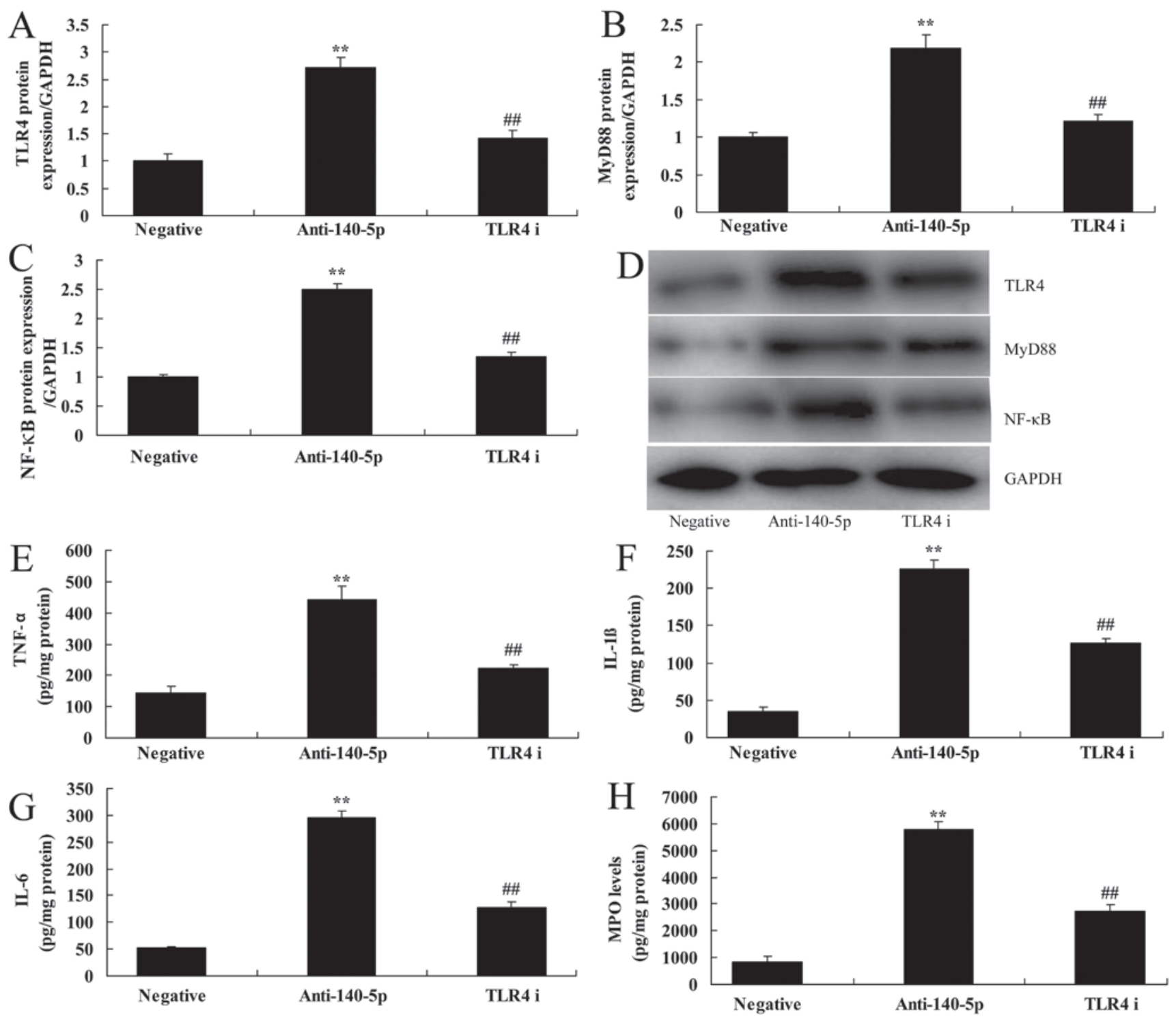

Figure 5. Inhibition of TLR4 suppresses the TLR4/MyD88/NF- $\mathrm{KB}$ signaling pathway and the effects of anti-miR-140-5p on the in vitro acute lung injury model. The protein expression of (A) TLR4, (B) MyD88 and (C) NF- $\mathrm{KB}$ was determined by (D) western blotting assays. The protein expression of (E) TNF- $\alpha$, (F) IL-1 $\beta$, (G) IL-6 and (H) MPO was also evaluated. " $\mathrm{P}<0.01$ vs. negative control group; ${ }^{\# \#} \mathrm{P}<0.01$ vs. anti-140-5p group. miR, microRNA; Anti-140-5p, downregulation of miR-140-5p group; TLR4 i, downregulation of miR-140-5p and TLR4 inhibitor group; TLR4, Toll-like receptor 4; MyD88, myeloid differentiation primary response 88 ; NF- $\mathrm{kB}$, nuclear factor- $\mathrm{kB}$; TNF- $\alpha$, tumor necrosis factor- $\alpha$; IL, interleukin; MPO, myeloperoxidase.

miR-140-5p down-regulation, in comparison with miR-140-5p down-regulation group (Fig. 6C-F).

\section{Discussion}

ALI and ARDS are acute respiratory distress syndromes caused by pulmonary capillary diffuse injury and enhanced permeability due to internal and external factors, mainly characterized by pulmonary edema, hyalinosis and atelectasis, with respiratory distress and refractory hypoxemia as clinical features (3). Internal pulmonary factors include direct injury to the lung, such as injury by stomach contents, lung injury, radiation injury, severe pneumonia, etc. External pulmonary factors consist of severe shock, endotoxemia, severe non-thoracic trauma, large area burns, large blood transfusion, acute pancreatitis and drug poisoning (12). In spite of recent great progress concerning the studies on ALI/ARDS, there is still a lack of effective clinical treatments in addition to protective mechanical ventilation (13). Therefore, it is urgent to explore a novel therapeutic strategy to alleviate ALI/ARDS (13). To the best of our knowledge, this is the first report demonstrating the suppressive expression of miR-140-5p in mice with ALI, compared with normal control group. Nagy et al (14) has showed that miR-140-5p regulates inflammation in cystic fibrosis.

At present, researches concerning the relationship between ALI/ARDS and miRNAs are still in early stage, and the study on human lung tissues and organs will provide direct and reliable evidence about the role of miRNA in ALI/ARDS (5). Our study showed that down-regulation of miR-140-5p significantly induced the levels of TNF- $\alpha$, IL-1 $\beta$, IL-6 and MPO in ALI in vitro. Li et al (15) reported that miR-140-5p inhibited inflammatory cytokines secretion through targeting TLR4.

ALI, a kind of severe lung infectious disease, is mainly caused by bacterial infection-induced sepsis. LPS, the main 

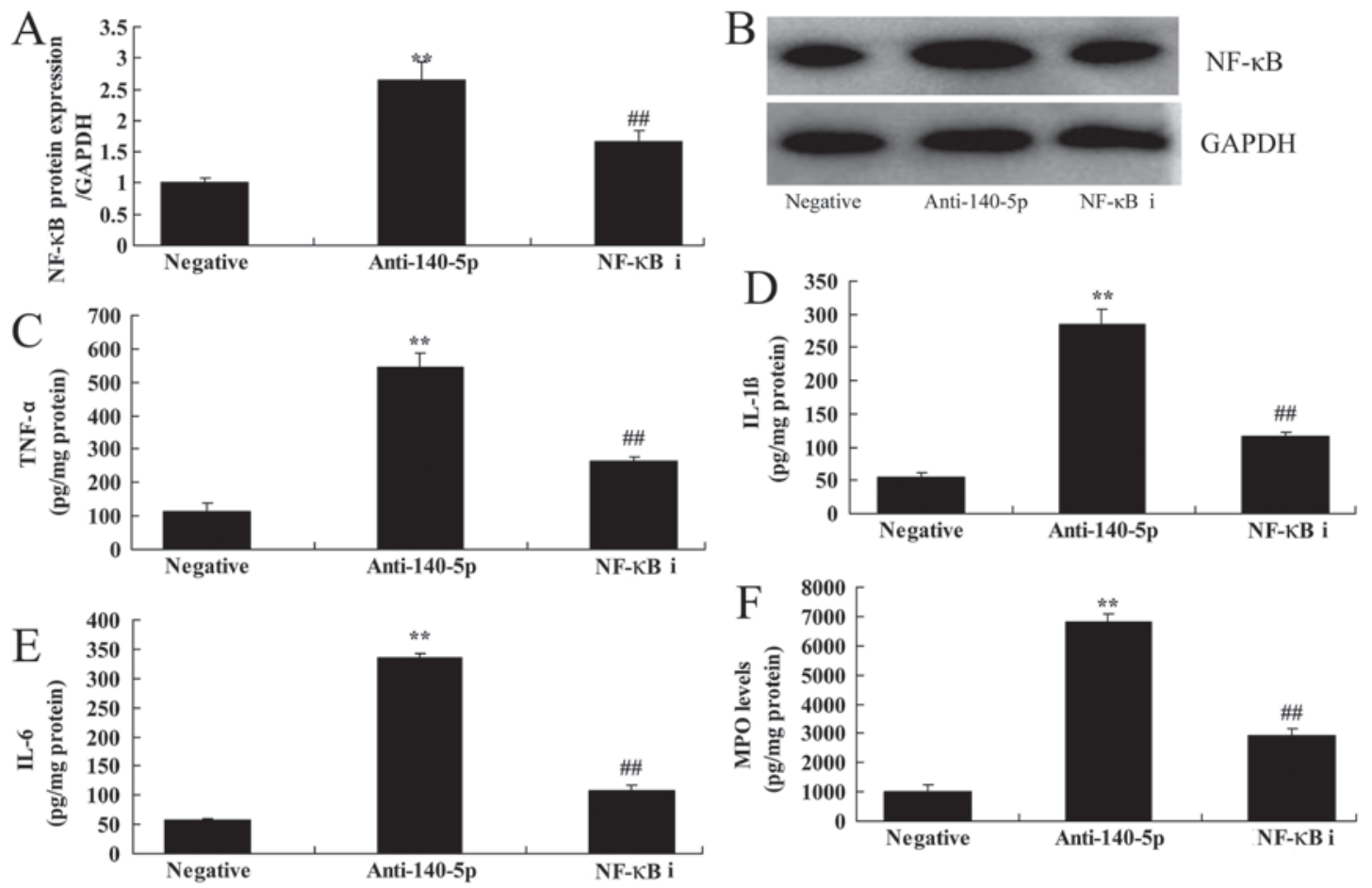

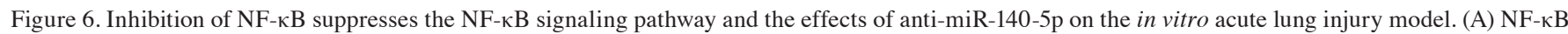
protein expression was determined by (B) western blot assays, as well as (C) TNF- $\alpha$, (D) IL-1 $\beta$, (E) IL-6 and (F) MPO levels. * $P<0.01$ vs. negative control

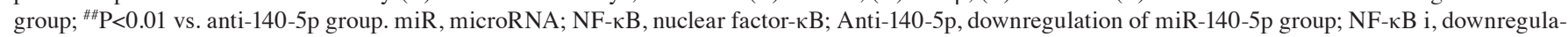
tion of miR-140-5p and NF- $\mathrm{BB}$ inhibitor group; TNF- $\alpha$, tumor necrosis factor- $\alpha$; IL, interleukin; MPO, myeloperoxidase.

component of the cell wall of gram negative bacteria, is the major pathogenic factor of ALI (9). LPS interacts with the receptor on the effector cell membrane to initiate an intracellular signal transduction system, which causes the activation of nuclear transcription factor $\mathrm{NF}-\kappa \mathrm{B}$, to initiate gene transcription and to produce a variety of proinflammatory cytokines. TLR4 is considered to be an important receptor mediating LPS signal transduction (16). MyD88, a key adaptor molecule in TLR4 signaling pathway, plays an important role in the transmission of upstream signaling as well as the incidence and progression of diseases (17). TLR4-mediated MyD88 signal pathway regulates the expression of multiple genes related to inflammation during immune response to pathogen invasion (18). Consistent with this finding, our studies showed that over-expression of miR-140-5p significantly suppressed TLR4/MyD88/NF-кB signaling pathway in in vitro model of ALI. Sun et al (19) suggest that miR-140-5p mediated the inflammation of human dental pulp stem cells through TLR4 signaling pathway.

$\mathrm{NF}-\kappa \mathrm{B}$, one of the downstream molecules of TLR4, is a heterodimer composed of p65 and p50 subunits (20). In the inactive state, $\mathrm{NF}-\kappa \mathrm{B}$ binds to inhibitive protein $\mathrm{I} \kappa \mathrm{B}$ and exists in the cytoplasm in an inactive form (21). Some studies have showed that in microglia, LPS activates TLR4, releases the inhibition of $\mathrm{NF}-\kappa \mathrm{B}$ by $\mathrm{I} \kappa \mathrm{B}$, promotes $\mathrm{NF}-\kappa \mathrm{B}$ nuclear translocation, and stimulates the expression of genes related to inflammation, thereby promoting the synthesis and release of IL-1 and TNF- $\alpha(21,22)$. We found that the inhibition of TLR4 using TLR4 inhibitor or NF- $\mathrm{B}$ inhibitor reduced the proinflammation of miR-140-5p in ALI in vitro through TLR4/MyD88/ NF- $\mathrm{B}$ signaling pathway. Jude et al (23) indicated that miR-140-3p regulated TNF- $\alpha$-induced CD38 expression in human airway smooth muscle cells through regulating the protein expression of p38 MAPK and NF- $\kappa B$.

Results from our current study suggest that miR-140-5p inhibits the inflammation of ALI via TLR4/MyD88/ NF- $\kappa \mathrm{B}$ signaling pathway. Our findings may provide a novel strategy of miR-140-5p for the treatment of ALI and protection against inflammation in further clinical research.

\section{Acknowledgements}

Not applicable.

\section{Funding}

No funding was received.

\section{Availability of data and materials}

The analyzed data sets generated during the study are available from the corresponding author on reasonable request.

\section{Authors' contributions}

JjL designed the experiments. YY, DL, YX, JL and BL performed the experiments. YY and JjL analyzed the data. JjL wrote the manuscript.

\section{Ethics approval and consent to participate}

The experimental procedures conformed to the Guide for the Care and Use of Laboratory Animals, and all of the procedures 
were approved by the Institutional Ethics Committee of Sichuan Cancer Hospital (Sichuan, China).

\section{Patient consent for publication}

Not applicable.

\section{Competing interests}

The authors declare that they have no competing interests.

\section{References}

1. Stapleton RD, Dixon AE, Parsons PE, Ware LB and Suratt BT; NHLBI Acute Respiratory Distress Syndrome Network: The association between BMI and plasma cytokine levels in patients with acute lung injury. Chest 138: 568-577, 2010.

2. Zhang Z, Chen L and Ni H: The effectiveness of Corticosteroids on mortality in patients with acute respiratory distress syndrome or acute lung injury: A secondary analysis. Sci Rep 5: 17654, 2015.

3. Braunschweig CA, Sheean PM, Peterson SJ, Gomez Perez S, Freels S, Lateef O, Gurka D and Fantuzzi G: Intensive nutrition in acute lung injury: A clinical trial (INTACT). JPEN J Parenter Enteral Nutr 39: 13-20, 2015.

4. Li W, Qiu X, Jiang H, Han Y, Wei D and Liu J: Downregulation of miR-181a protects mice from LPS-induced acute lung injury by targeting Bcl-2. Biomed Pharmacother 84: 1375-1382, 2016.

5. Cao Y, Lyu YI, Tang J and Li Y: MicroRNAs: Novel regulatory molecules in acute lung injury/acute respiratory distress syndrome. Biomed Rep 4: 523-527, 2016.

6. Yang K, Gao B, Wei W, Li Z, Pan L, Zhang J, Zhao Q, Chen W and $\mathrm{Xu} \mathrm{Z}$ : Changed profile of microRNAs in acute lung injury induced by cardio-pulmonary bypass and its mechanism involved with SIRT1. Int J Clin Exp Pathol 8: 1104-1115, 2015.

7. Wang X, Zhang L, Duan W, Liu B, Gong P, Ding Y and Wu X: Anti-inflammatory effects of triptolide by inhibiting the NF-kappaB signalling pathway in LPS-induced acute lung injury in a murine model. Mol Med Rep 10: 447-452, 2014.

8. He X, Qian Y, Li Z, Fan EK, Li Y, Wu L, Billiar TR, Wilson MA Shi X and Fan J: TLR4-upregulated IL-1beta and IL-1RI promote alveolar macrophage pyroptosis and lung inflammation through an autocrine mechanism. Sci Rep 6: 31663, 2016.

9. Sun XJ, Li XQ, Wang XL, Tan WF and Wang JK: Sevoflurane inhibits nuclear factor-kappaB activation in lipopolysaccharide-induced acute inflammatory lung injury via toll-like receptor 4 signaling. PLoS One 10: e0122752, 2015.

10. Zhang $\mathrm{Y}$ and $\mathrm{Xu} \mathrm{J}$ : miR-140-5p regulates hypoxia-mediated human pulmonary artery smooth muscle cell proliferation, apoptosis and differentiation by targeting Dnmt1 and promoting SOD2 expression. Biochem Biophys Res Commun 473: 342-348, 2016.

11. Livak KJ and Schmittgen TD: Analysis of relative gene expression data using real-time quantitative PCR and the 2(-Delta Delta C(T)) method. Methods 25: 402-408, 2001.
12. Feiner JR, Gropper MA, Toy P, Lieberman J, Twiford J and Weiskopf RB: A clinical trial to detect subclinical transfusion-induced lung injury during surgery. Anesthesiology 123: 126-135, 2015.

13. Zheng G, Huang L, Tong H, Shu Q, Hu Y, Ge M, Deng K, Zhang L, Zou B, Cheng B and Xu J: Treatment of acute respiratory distress syndrome with allogeneic adipose-derived mesenchymal stem cells: A randomized, placebo-controlled pilot study. Respir Res 15: 39, 2014

14. Nagy B Jr, Nagy B, Fila L, Clarke LA, Gönczy F, Bede O, Nagy D, Újhelyi R, Szabó Á, Anghelyi A, et al: Human epididymis protein 4: A novel serum inflammatory biomarker in cystic fibrosis. Chest 150: 661-672, 2016.

15. Li H, Guan SB, Lu Y and Wang F: miR-140-5p inhibits synovial fibroblasts proliferation and inflammatory cytokines secretion through targeting TLR4. Biomed Pharmacother 96: 208-214, 2017.

16. Chi X, Wei X, Gao W, Guan J, Yu X, Wang Y, Li X and Cai J: Dexmedetomidine ameliorates acute lung injury following orthotopic autologous liver transplantation in rats probably by inhibiting Toll-like receptor 4-nuclear factor kappa B signaling. J Transl Med 13: 190, 2015.

17. Liu DD, Cao G, Han LK, Ye YL, Zhang Q, Sima YH and Ge WH: Flavonoids from Radix Tetrastigmae improve LPS-induced acute lung injury via the TLR4/MD-2-mediated pathway. Mol Med Rep 14: 1733-1741, 2016.

18. Xu L, Xue T, Zhang J and Qu J: Knockdown of versican V1 induces a severe inflammatory response in LPS-induced acute

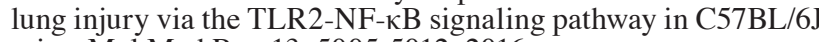
mice. Mol Med Rep 13: 5005-5012, 2016.

19. Sun DG, Xin BC, Wu D, Zhou L, Wu HB, Gong W and Lv J: miR-140-5p-mediated regulation of the proliferation and differentiation of human dental pulp stem cells occurs through the lipopolysaccharide/toll-like receptor 4 signaling pathway. Eur J Oral Sci 125: 419-425, 2017.

20. Jiang Q, Yi M, Guo Q, Wang C, Wang H, Meng S, Liu C, Fu Y, $\mathrm{Ji} \mathrm{H}$ and Chen T: Protective effects of polydatin on lipopolysaccharide-induced acute lung injury through TLR4-MyD88-NF-kB pathway. Int Immunopharmacol 29: 370-376, 2015.

21. Tianzhu $Z$ and Shumin W: Esculin inhibits the inflammation of LPS-induced acute lung injury in mice via regulation of TLR/NF- $\kappa$ B pathways. Inflammation 38: 1529-1536, 2015.

22. Zhang X, Sun CY, Zhang YB, Guo HZ, Feng XX, Peng SZ, Yuan J, Zheng RB, Chen WP, Su ZR and Huang XD: Kegan Liyan oral liquid ameliorates lipopolysaccharide-induced acute lung injury through inhibition of TLR4-mediated NF- $\mathrm{BB}$ signaling pathway and MMP-9 expression. J Ethnopharmacol 186: 91-102, 2016.

23. Jude JA, Dileepan M, Subramanian S, Solway J, Panettieri RA Jr, Walseth TF and Kannan MS: miR-140-3p regulation of TNF- $\alpha$-induced CD38 expression in human airway smooth muscle cells. Am J Physiol Lung Cell Mol Physiol 303: L460-L468, 2012.

This work is licensed under a Creative Commons

Attribution-NonCommercial-NoDerivatives 4.0 International (CC BY-NC-ND 4.0) License. 